\title{
Assessment of Construction Waste Management Practice in Mekelle, northern Ethiopia: Challenges and Opportunities
}

\author{
Tewodros Alemayehu ${ }^{1 *}$, Abdulaziz Osman ${ }^{2}$ and Haddush Goitom² \\ ${ }^{1}$ School of Earth Sciences, College of Natural and Computational Sciences, P.O. Box 231, Mekelle \\ University, Mekelle, Ethiopia(*tewodros.ale@gmail.com). \\ ${ }^{2}$ School of Civil Engineering, EIT-M, Mekelle University, P.O. Box 231, Mekelle, Ethiopia.
}

\begin{abstract}
The rapid economic growth and urbanization in Ethiopia have led to extensive construction activities in major cities. Construction activities have known to generate large quantities of wastes that pose serious environmental problems. This paper presents the challenges of construction waste management practices in Mekelle city and explores appropriate measures to address the issues in a more sustainable way. Field observation, questionnaire survey, interviewing of public sector officials at different levels was conducted to identify the source and management options of construction waste in the city. The findings showed that the majority of survey participants felt that their firms have taken various measures to manage construction waste. It was revealed that $40 \%$ of the respondents exercise illegal dumping as a common method of waste management, which is closely followed by reuse and recycling. It is evident that over $75 \%$ of the constructiongenerated has potential for recycling and reuse as backfilling and base for roads and buildings. The increase in the number of illegal dumping sites in the city represents the failure to properly control and implement effective construction waste management. It was suggested that sustainable solution for construction waste management at local level depends on increasing awareness and promoting reusing and recycling of construction waste.
\end{abstract}

Keywords: Construction waste, Disposal, Illegal dumping, Waste management, Mekelle.

\section{INTRODUCTION}

The rapid economic growth and urbanization has led to extensive construction activities in the major cities of Ethiopia. The increased construction activities have known to generate large quantities of wastes causing social, environmental, and economic crisis (Kartam et al., 2004; Marzouk and Azab, 2014; Taffese, 2018). Over the years, generation of construction and demolition (C \& D) waste has increased significantly in Ethiopia (Yehualaw and Woldesenbet, 2016; Taffese, 2018). The construction and demolition waste comprised of different types of wastes arising from demolition, site clearance, land excavation, building construction etc. The construction wastes can be inert, consists of debris, soil, or non-inert construction waste, represent organic materials (Luangcharoenrat et al., 2019). 
The massive production of $\mathrm{C} \& \mathrm{D}$ waste is the result of inefficient construction and waste management practices (Taffese, 2018). The increased C \& D waste can lead to dumping of considerable quantities of construction materials and increasing number of illegal dumpsites (Mahayuddin et al., 2008). The construction waste that ends up in landfills accounts for $13 \%$ to $60 \%$ of the total amount of waste in different countries (Luangcharoenrat et al., 2019). The conventional approach of construction waste is the direct disposal into the landfill. Nevertheless, due to scarcity of land and environmental and social concerns, landfill is probably the least desirable option of waste management. Dumping large quantities of C \& D waste in landfill is unfeasible both economically and environmentally (Kartam et al., 2004). Furthermore, the lack of proper construction waste disposal site increases the demand for available space for dumping. The construction wastes often occupy open space and roadsides that could potentially be used for various developments. Such illegal dumping of C \& D waste is a significant management concern for many local governments because of the environmental and land issues. The uncontrolled disposal of $\mathrm{C} \& \mathrm{D}$ waste greatly contributes to environmental degradation making the rehabilitation processes difficult (Jakiel et al., 2019). The fact that illegal dumping of construction wastes become an increasingly large problem in major cities raise the need for better management through minimization of waste generation, resource recovery and recycling in order to reduce the volume of landfills (e.g. Fadiya et al., 2014; Luangcharoenrat et al., 2019).

The growing demand for effective C \& D waste management has led to a significant increase in the research activities worldwide (e.g. Kartam et al., 2004; Mahayuddin et al., 2008). Scientific studies have revealed that management strategies that focus on reducing, re-using, and recycling of C \& D waste contributes for sustainable waste management (Nagapan et al., 2012; Ram and Kalidindi, 2017). It was further stated that source reduction and redirecting recyclable material back into the construction process that would otherwise be end up at the disposal sites remain the highest priority. There has been a growing interest in the resource recovery in construction activities to save landfill places and achieve sustainable solutions in Ethiopia (Taffese, 2018). In addition to its negative impact on the environment, the construction waste requires sizable land for dumping and significant management costs. Studies suggested that reliable information on the source and amount of waste generated is important for effective waste management (Wu et al., 2014; Luangcharoenrat et al., 2019). Several quantitative methods in the 
form of survey questionnaire have been used to evaluate the source and composition of construction waste (e.g. Fadiya et al., 2014; Ikau et al., 2016).

In recent years, the illegal dumping of construction waste in Mekelle has gained the attention of public and authority due to environment and safety concerns. The wastes generated by the construction have been increasing and is not well managed, thereby causing considerable problems. The lack of knowledge on source and characteristics of construction waste influences the handling of the waste properly. Illegal waste disposal and its spatial patterns also contribute to the inadequate waste management efforts (Glanville and Chang, 2015). Therefore, it is important to identify the source and cause of construction waste and the amount of recyclable materials to implement effective management plans. To the best of our knowledge, no research related to the source and management of C \& D waste has been conducted in the study area (Mekelle city). This paper presents the possible source of construction waste and spatial analysis of dumping site with a view to providing information on the status of the construction waste management practices in Mekelle city. The study offers better understanding to the challenges and opportunities of C \& D waste management in Mekelle.

\section{CONSTRUCTION WASTE IN MEKELLE}

This study has been conducted in Mekelle, one of the major cities of Ethiopia. The city is currently in dynamical state of growth and spatial expansion. The Mekelle city is covering an area of 26,872 hectare and is divided into seven administrative sub-cities. The topography of the watershed is characterized by flat and rolling mountains. The hilly terrain is situated at the northern fringe of the city and extends further to the east where shale/limestone and dolerite rocks are outcropped. The weathering products of these rocks have contributed to the soil formation by depositing sediment over flat land. Mekelle is characterized by a semi-arid climate condition and the rainfall pattern is bimodal type with more than $70 \%$ of the rainfall occurring in wet season (i.e., JuneSeptember).

With a dynamic population growth, the construction sector is growing rapidly in the city. The increased construction activities generate large quantities of waste causing serious environmental concern in the city. High rate of illegal dumping of construction wastes become an increasingly severe problem due to poor waste management practice. Although the problem has been known for years, the issues of illegal dumping have been exacerbated rapidly due to new 
development in infrastructure and building recently. It is evident that lack of proper construction waste management is a critical issue for local governments to deal with.

The government regulation that deals with solid waste management including C \& D waste is enacted in Proclamation No. 513/2007. According to the law, city administrations are delegated to ensure environmentally sound construction waste management. The cities have the responsibility to regulate illegal dumping to safeguard the safety and health of the communities and environment. Despite of the efforts by the authority to enforce regulation through imposing of fines on illegal dumping, the issue remains unsolved. The monitoring measures undertaken to regulate the uncontrolled dumping is very limited. The current management practice cannot effectively address the growing $\mathrm{C} \& \mathrm{D}$ waste generation.

\section{METHODOLOGY}

The research methodology adopted in this study includes survey questionnaire, site visit and document review. Questionnaire provides firsthand information on the sources and practices of $\mathrm{C}$ $\& \mathrm{D}$ waste management. The questionnaires were designed based on the review of the previous studies, and current observation of the C \& D waste management in the city.

\subsection{Sampling and Data Collection}

The survey, quantitative, was developed to understand the perception and opinion of the respondents on source of construction waste, recycling practice and illegal dumping activities. Questionnaire is used effectively in several construction waste management studies (Ikau et al., 2016). Questionnaire in the present study was administered through convenience sampling technique from 25 selected construction firms operating locally. The respondents consist of project managers and site engineers with extensive work experience in construction projects. The questionnaire consists of two sections. The first part seeks the background information of the construction company and the respondents. The second part focuses on major sources of construction waste, waste management preference and waste minimization measures. Face to face interviews were conducted with city and sub-city- level experts of sanitation and beautification offices to further elicit responses on current problems of waste management.

\subsection{Data Analysis}

The data gathered from both primary and secondary sources were analyzed qualitatively and quantitatively. Responses to structured questionnaire were analyzed quantitatively by correlating 
the frequency of responses to each of the questions. Collected data was analyzed using SPSS software and Microsoft Excel. The processed data is then interpreted to provide in-depth information regarding to the source, cause and handling of construction waste. Furthermore, it is important to note that the qualitatively data seeks to understand the most common construction waste management measures employed by the firms.

The survey questionnaire was accompanied by site observations. Observations were made regarding the current practices and situations on the sites. The field observations and documentation review assist to establish clear understanding on the current status of C \& D waste management measures in order to identify appropriate interventions. Field visit was conducted during August and September 2019 to record the number and situation of the dumpsites within the study area (Fig 1). The dumping sites were recorded using a handheld GPS device and then mapped using ArcGIS software. The mapping is intended to establish the relationships between the surrounding environment and illegal dumping sites so that to implement appropriate remedial measures (Paz et al., 2018).

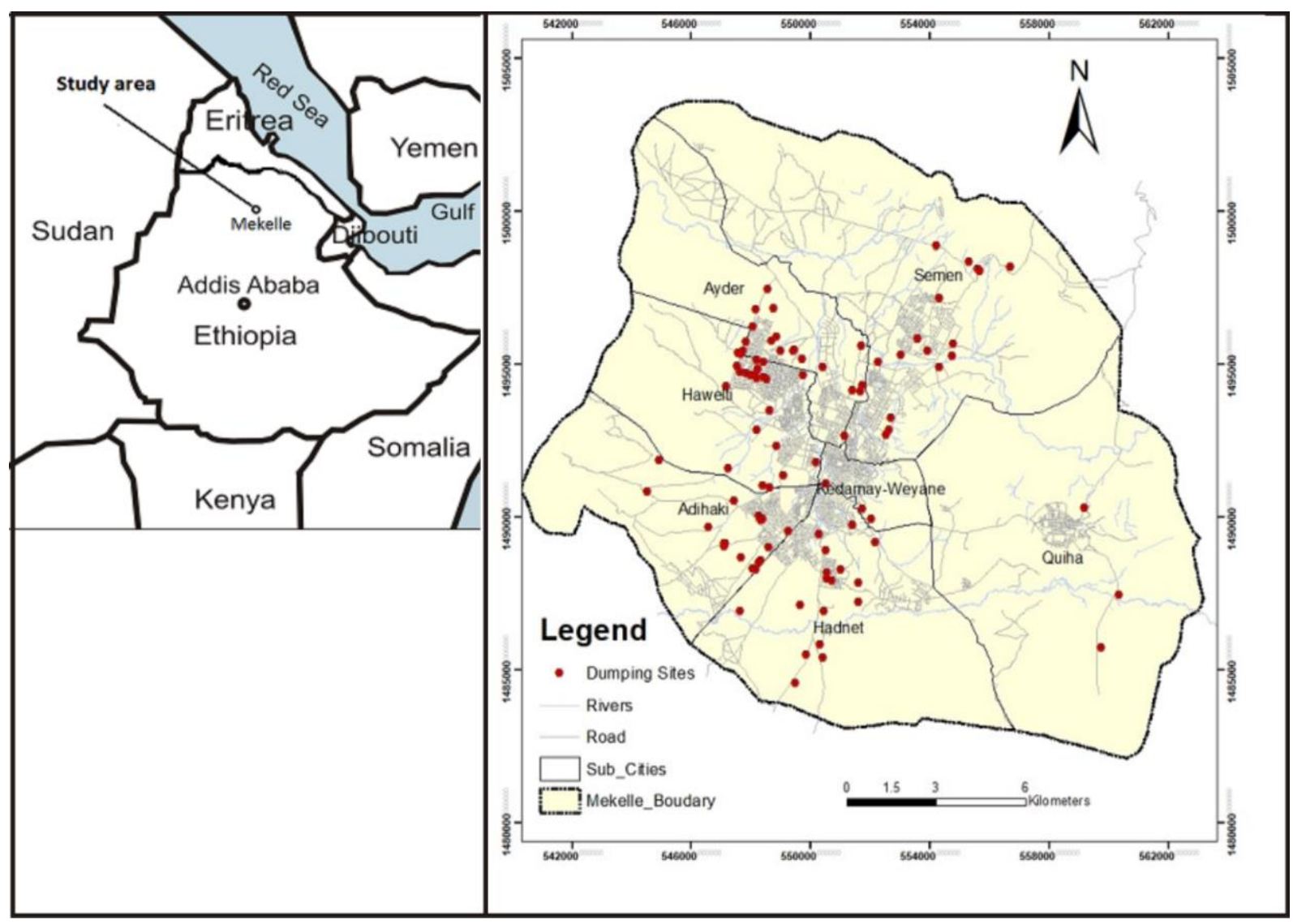

Figure 1. Location and spatial distribution of the waste dumpsite in Mekelle city. 


\section{RESULTS}

\subsection{Sources of Construction Waste}

To address the $\mathrm{C} \& \mathrm{D}$ waste management, it is important to identify the sources of construction waste (Fadiya et al., 2014). Road network, excavated material, demolition waste, site clearance and renovation waste are identified as sources of C \& D waste by Tam et al. (2007). In this context, the respondents were asked regarding source of construction waste. Accordingly, $44 \%$ of the respondents indicated that the biggest source of construction waste is earth work (such as, excavation) (Fig 2). Demolishing of houses has been recognized as a next common contributor to construction waste by $28 \%$ survey participants. Due to the fact that demolition waste was highly reused by most of construction companies and their quantity in the dumping sites was very small. $24 \%$ of the respondents thought that many wasteful activities have taken place during construction processes. Construction waste materials in most illegal dumping sites tend to be heterogeneous. The waste mainly consists of soil/stone, cement/plaster and concrete from excavation and construction site. A study suggested that the masonry debris accounts for about $76 \%$ of the total quantity of demolition debris (Ram and Kalidindi, 2017).

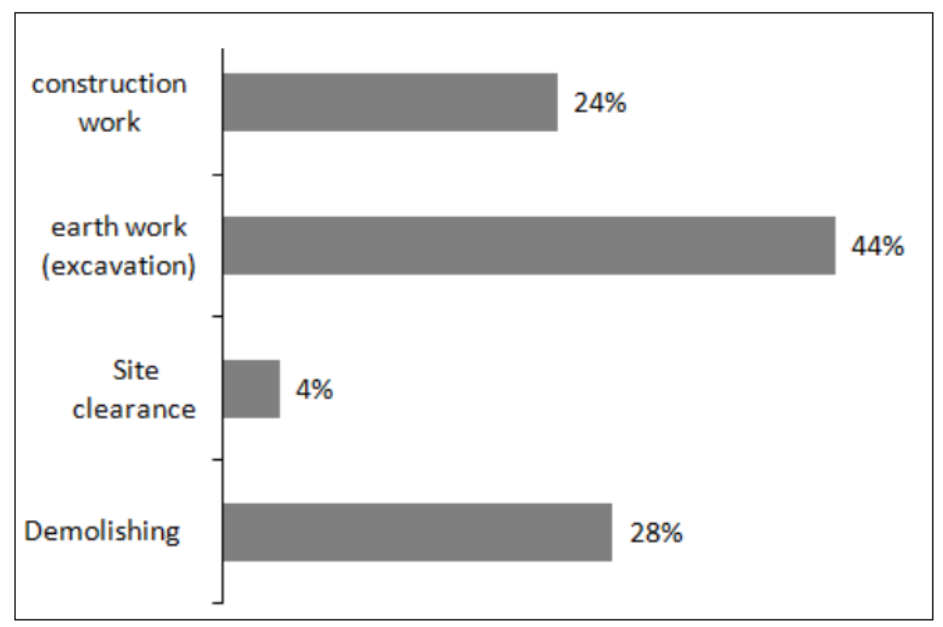

Figure 2. Source of C \& D waste in Mekelle City.

\subsection{Illegal Dumping Activities}

Illegal dumping is widely practiced activities for discarding of C \& D waste in Mekelle city. An increasing amount of construction and demolition waste is being disposed illegally at different locations. During a field visit in August and September of 2019, it was observed that as many as 94 illegal C \& D waste disposal sites were identified. The spatial distribution of the dumping sites 
is mapped to get the extent of the problems. Mapping of illegal dumping sites provide information on potentially vulnerable area for unlawful disposal (Mihai et al., 2013; Paz et al., 2018). It places emphasis to areas that demand special attention by the authority to control and monitor the illegal dumping (Jakiel et al., 2019). Most of the illegal dumping sites are concentrated at outskirts of the city in open areas where controlling and monitoring is difficult. About $16 \%$ of illegal dumping happens to be in the farmland. The dumping sites have been operating for years; although the opening of authorized dumping sites came along with the start of big construction projects. The designated disposal facilities are known to local officials and are randomly distributed around the city without following proper site selection procedures. Disposal permit is given to contractors to dispose their waste in temporarily designated dumping sites and access to the dumping sites is unrestricted.

Respondents were also asked if they follow appropriate procedures to dispose construction waste. About $40 \%$ of the respondents reveal that they implement improper construction waste management practice by dumping the waste unlawfully (Fig 3). Only $24 \%$ respondents adopted proper way of managing construction waste by sending construction waste to designated disposal sites. However, the lack of enough number of construction waste disposal site and transportation cost contributes to illegal dumping.

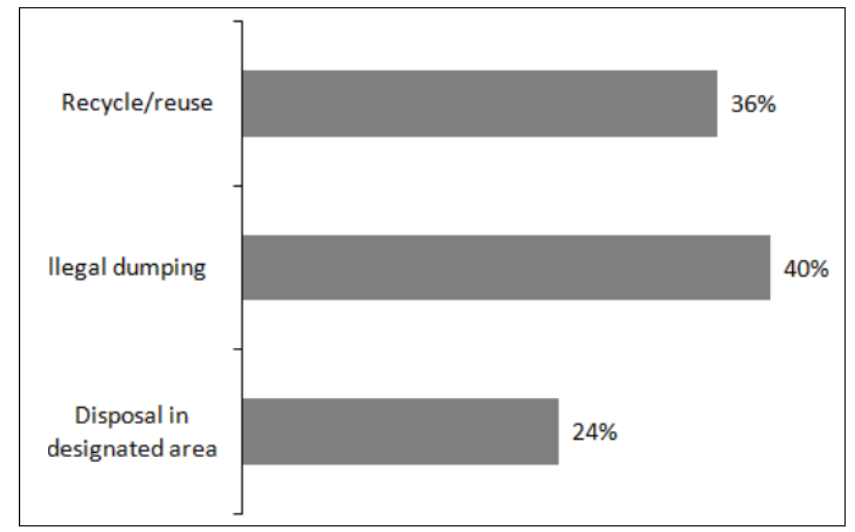

Figure 3. Preference of construction waste management practices by survey participants.

The city administration has found monitoring and controlling illegal dumping very difficult considering the lack of coordination, weak enforcement, and absence of proper dumping facilities.

\subsection{Impact of Construction Waste}

Illegal waste disposal has been identified as a major environmental degradation practices in the world (e.g. Mahayuddin et al., 2008; Mihai, 2019). In recent years, the increase in C \& D waste in 
Mekelle city and subsequent improper handling has become a critical issue. It is normal to observe heaps of construction waste along the roadside and open space, causing major problem. The size of most of the illegal dumping sites in Mekelle appears to be small. However, five of the designated dumping sites occupy significant space and form large heaps of construction waste. The presence of illegal waste degrades land value at the disposal site and surroundings and often changes the landscape. The dumping sites are currently unregulated and their size swells rapidly and it is feared landslide may be triggered (Yang et al., 2017). The city municipality occasionally performs leveling of the dumping site and backfilling to manage pilling of waste. The dumping of construction waste makes residential areas more vulnerable to flooding when it blocks storm water drains and trenches. According to municipal officials the occurrence of water overflow due to dumping of construction waste in the roadsides has been reported in several part of the city. The illegal dumping of construction waste in roads, trenches and drainage is known to induce floods in many parts of the world (Ram and Kalidindi, 2017).

The existing illegal construction dumping sites can potentially cause serious soil and water pollutions (Kartam et al., 2004; Mihai, 2019).The respondents were also asked if they think the construction waste contains hazardous material and majority of them $(60 \%)$ revealed that the construction waste may contain hazardous substance. However, the participants admit that they are not aware if they contribute environmental pollution which may be attributed to lack of understanding.

Most of the disposal sites are in the proximity of built-up areas and are aesthetically unattractive as result of landscape change. In addition, such illegal dumping sites can cause disruption to traffic, blocking of drains and change to soil condition (Fadiya et al., 2014). The local communities are uninformed of the negative consequences of the increasing illegal dumping activities and do little to prevent it.

\subsection{Reuse and Recycling of C \& D Waste}

It is recognized that construction waste generation is inevitable, and thus focusing on source reduction, reuse and recycling of the waste material with the view of reducing the quantity of landfill waste is important (Nagapan et al., 2012; Yeheyis et al., 2013; Fadiya et al., 2014).

Survey participants were asked if reuse and recycling of construction waste is employed as means of management at present. $36 \%$ of respondents claimed that recycling and reusing is practiced on their organization (Fig 3). However, survey showed that not more than $10 \%$ of 
construction waste is reused/recycled by these construction firms that practice it (Fig 4). The construction waste is mainly used as backfilling and road base applications. Of the respondents who have practiced recycling/reusing in their organization, $45 \%$ refers environmental awareness and 35\% cost reduction as the main reasons for recycling materials back into construction process. Majority respondents felt that recycling construction waste promote environmentally friendly management practice. Furthermore, it was mentioned by the respondents that landfill taxes would discourage illegal dumping of construction and demolition waste.

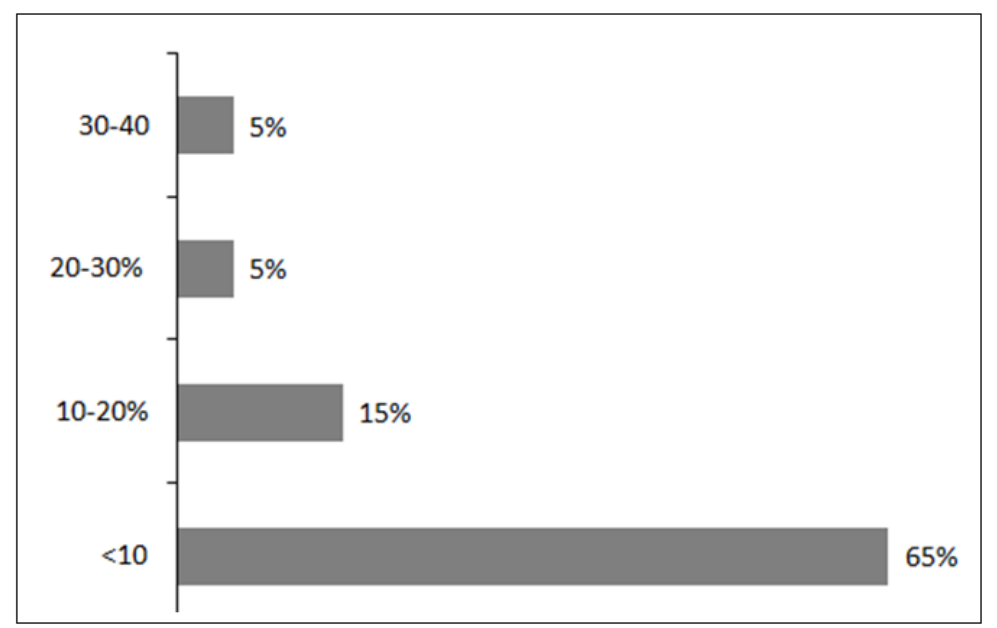

Figure 4. The approximate percentage of the construction waste that is being reused/recycled.

\section{DISCUSSION}

The integrated waste management strategy promotes the $3 \mathrm{R}$ (reduce, re-use and recycle) waste management practices (Yeheyis et al., 2013; Mihai, 2019). The approach provides an opportunity to utilize construction resources and minimizing the amount of valuable land for dumping (Kartam et al., 2004). Such sustainable waste management strategy allows achieving resource recovery as well as protecting environment. The general observation from the survey shows that even though the construction firms have the willingness to implement reusing and recycling, the practice is not widely adopted. Based on the current practice, landfilling is considered the easiest way to manage waste. Consistent with research conducted elsewhere, the spatial distribution of the illegal dumping sites is associated with a range of geographical attribute such as accessibility, proximity to the construction projects and availability of vacant space (e.g. Glanville and Chang, 2015; Jakiel et al., 2019). The existing illegal dumping sites are totally unprotected and need immediate actions. It is essential to rehabilitate the degraded landscape and explore suitable landfill sites for future 
use. Dumping waste in approved sites would also help to accurately keep records of the quantity and quality of the C \& D waste (Ram and Kalidindi, 2017).

The municipality pays less attention to monitoring and selection of appropriate dumping site. The lack of regulation and guideline are regarded as contributing factor for selection of unsuitable dumping sites and unsustainable use of land resource (Yeheyis et al., 2013). Sustainable solution can be achieved by introducing regulatory measures that could support waste minimization (Yeheyis et al., 2013; Jin et al., 2017) and reliable information on the construction waste generated is critical (Wu et al., 2014). Reliable data on magnitude and characteristics of C $\&$ D waste in many countries help to develop sustainable management plan (Ram and Kalidindi, 2017).

It is apparent that the city administration must adopt long-term proper waste management practice that encourage recycling and reuse rather than disposal. The enactment of construction waste regulation significantly helps to improve waste management and divert construction wastes into useful resources (Jin et al., 2017). It is time for the city to implement measures that control and monitor illegal dumping sites to improve current waste management practice. It is also recognized that the solution to better waste management depends on the commitment and effort of construction firms to employ sound management measures and to comply with relevant regulations (Sapuay, 2016).

There is a substantial opportunity for re-use or recycle of construction waste if adequate awareness is created. Better waste management system needs the cooperation of all parties involved (Mahayuddin et al., 2008). In fact, the construction players have significant role to play in promoting good practices in construction waste management. Reuse of construction waste has top priority considering backfilling is the preferred waste diversion practice by the construction contractors. The soil and stone material are frequently reused and recycled (Fig 5). Excavated soil and rock can be used for backfilling without reprocessing (Magnusson et al., 2015). Previous studies suggested the prospect of concrete aggregate recovery from demolished concrete waste (Yehualaw and Woldesenbet, 2016; Mihai, 2019). Therefore, initiating and promoting reuse and recycling of construction waste significantly contribute to improved waste management practice and minimize the number and size of illegal dumping in the city. 


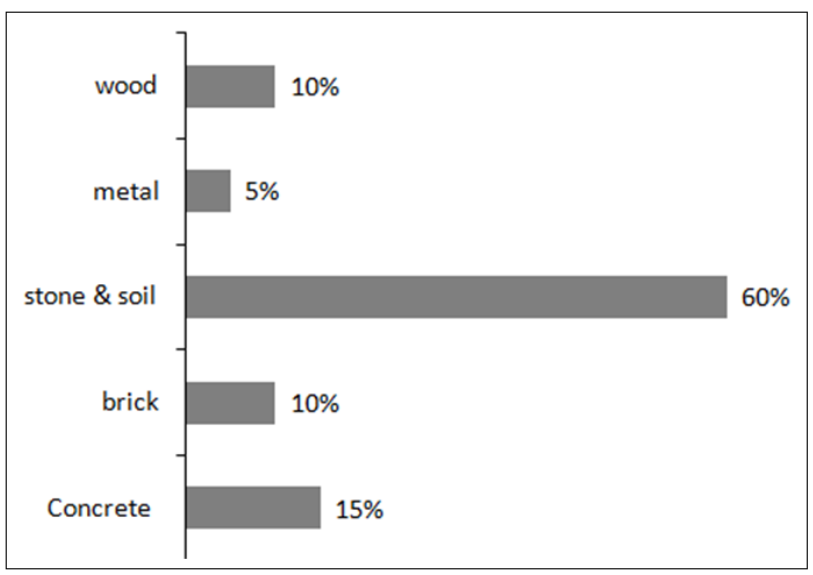

Figure 5. The type of construction waste materials that are frequently reused/recycled.

\section{CONCLUSION}

This study presents the current C \& D waste management practice in Mekelle where the waste generation is growing very rapidly, and illegal dumping is widespread and unregulated. The higher number of illegal dumping sites in the city represents the failure to properly control and implement effective construction waste management.

The construction waste management focuses on disposal whilst reuse and recycling activities are less practiced. The qualitative and quantitative analysis revealed that illegal dumping is identified by majority of the respondents as most preferable method followed by reuse and recycle. It is evident that over $75 \%$ of the construction waste generated has the potential to be recycled and reused if adequate awareness is created. Majority participants felt that recycling construction waste contributes environmentally friendly management practice.

Considering the growing generation of construction waste, the city administration must adopt an integrated waste management approach that promotes reduce, reuse and recycling rather than disposal. Enacting relevant regulation could support source reduction, reuse, and recycle that minimize the number and size of illegal dumping in the city. It is recognized that effective waste management needs the cooperation of all relevant parties, including the city administration to control illegal dumping sites.

It is suggested that the long-term sustainable solution for construction waste management at local level depends on increasing adequate awareness and promoting reusing and recycling of waste materials. 


\section{ACKNOWLEDGEMENTS}

The authors would like to thank the construction firms for active involvement in surveys. We would also like to acknowledge the anonymous reviewers for their constructive comments on manuscript.

\section{CONFICT OF INTEREST}

There are no conflicts of interests.

\section{REFERENCE}

Fadiya, O.O., Georgakis, P \& Chinyio, E. 2014. Quantitative analysis of the sources of construction waste. Journal of Construction Engineering, 1-9 (doi:10.1155/2014/651060).

Glanville, K \& Chang, H.C. 2015. Mapping Illegal Domestic Waste Disposal Potential to Support Waste Management Efforts in Queensland, Australia. International J. Geographical Information Science, 29(6): 1042-1058 (doi:10.1080/13658816.2015.1008002).

Ikau, R, Joseph, C \& Tawie, R.2016. Factors influencing waste generation in the construction industry in Malaysia. Procedia - Social and Behavioral Sciences, 234: 11-18.

Jakiel, M., Bernatek-Jakiel, A., Gajda, A., Filiks, M \& Pufelska, M. 2019. Spatial and temporal distribution of illegal dumping sites in the nature protected area: the Ojców National Park, Poland. Journal of Environmental Planning and Management, 62(2): 286-305 (doi: 10.1080/09640568.2017.1412941).

Jin, R., Li, B., Zhou, T., Wanatowski, D \& Piroozfar, P. 2017. An empirical study of perceptions towards construction and demolition waste recycling and reuse in China. Resources, Conservation and Recycling, 126: 86-98.

Kartam, N., Al-Mutairi, N., Al-Ghusain, I \& Al-Humoud, J. 2004. Environmental management of construction and demolition waste in Kuwait. Waste Management, 24(10): 1049-1059.

Luangcharoenrat, C., Intrachooto, S., Peansupap, V \& Sutthinarakorn, W. 2019. Factors Influencing Construction Waste Generation in Building Construction: Thailand's Perspective. Sustainability, 11(13): 1-17 (doi: 10.3390/su11133638).

Magnusson, S., Lundberg, K., Svedberg. B \& Knutsson, S. 2015. Sustainable Management of Excavated Soil and Rock in Urban Areas - A Literature Review. Journal of Cleaner Production, 93: 18-25 (doi:10.1016/j.jclepro.2015.01.010). 
Mahayuddin, S.A., Pereira, J.J., Badaruzzaman, W.H.W \& Mokhtar, M. 2008. Construction waste management in a developing country: Case study of Ipoh, Malaysia. WIT Transactions on Ecology and the Environment, 109: 481-489.

Marzouk, M \& Azab, S. 2014. Environmental and economic impact assessment of construction and demolition waste disposal using system dynamics. Resources, Conservation and Recycling, 82: 41- 49

Mihai, F. C. 2019. Construction and Demolition Waste in Romania: The Route from Illegal Dumping to Building Materials. Sustainability, 11(11): 1-20 (doi:10.3390/su11113179).

Mihai, F.C., Ursu, A., Ichim, P \& Chelaru, D. 2013. Determining Rural Areas Vulnerable to Illegal Dumping Using GIS Techniques. Case study: Neamt County, Romania. Conference Proceedings of 13th International Multidisciplinary Scientific GeoConference on Ecology, Economics, Education and Legislation, SGEM, 1: 275-282.

Nagapan, S., Rahman, I.A., de Asmi, A., Memon, A.H \& Latif, I. 2012. Issues on construction waste: the need for sustainable waste management. IEEE Colloquium on Humanities, Science and Engineering Research, Kota Kinabalu, Sabah, Malaysia, pp. 325-330.

Paz, D.H.F.D., Lafayette, K.P.V \& Sobral, M.D.C. 2018. GIS-based planning system for managing the flow of construction and demolition waste in Brazil. Waste Management and Research, 36: 541-549.

Ram, V.G \& Kalidindi, S.N. 2017. Estimation of construction and demolition waste using waste generation rates in Chennai, India. Waste Management \& Research, 35(6): 610-617.

Sapuay, S.E. 2016. Construction waste - potentials and constraints. Procedia Environmental Sciences, 35: 714-722.

Taffese, W.Z. 2018. Suitability investigation of recycled concrete aggregates for concrete production: an experimental case study. Advances in Civil Engineering, vol. 2018, Article ID 8368351, 11p (https://doi.org/10.1155/2018/8368351).

Tam, V.W.Y., Shen, L.Y., Fung, I.W.H. \& Wang, J.Y. 2007.Controlling Construction Waste by Implementing Governmental Ordinances in Hong Kong. Journal of Construction Innovation, 7: 149-166.

Wu, Z., Yu, A.T.W., Shen, L.Y \& Liu, G. 2014. Quantifying construction and demolition waste: An analytical review. Waste Management, 34(9): 1683-1692. 
Yang, H., Xia, J., Thompson, J.R \& Flower, R.J. 2017. Urban construction and demolition waste and landfill failure in Shenzhen, China. Waste Management, 63: 393-396.

Yeheyis, M., Hewage, K \& Alam, M.S. 2013. An overview of construction and demolition waste management in Canada: A lifecycle analysis approach to sustainability. Clean Technologies and Environmental Policy, 15: 81-91.

Yehualaw, M.D \& Woldesenbet, A.K. 2016. Economic impacts of recycled concrete aggregate for developing nations: a case study in the Ethiopian construction industry. In Construction Research Congress, pp. 250-259, American Society of Civil Engineers, San Juan, PR, USA. 